\title{
OS CONCEITOS DE “SEMELHANÇA”, “DIFERENÇA” E “IDENTIDADE” EM FOUCAULT E SUAS RELAÇÕES COM A CRÍTICA IMPRESSIONISTA BRASILEIRA: A PRESENÇA DE ESPAÇOS LITERÁRIOS NO TEXTO CRÍTICO
}

Nelson Ricardo Guedes dos Reis

Doutor em Letras: Literatura Comparada - UFMG

\begin{abstract}
RESUMO
Para Foucault, o processo epistemológico da civilização ocidental passa por três momentos: até o século 16, esteve ligado ao conceito de semelhança; a partir desse século, até o século 19, ao conceito de diferença. No século 20, a relação dos elementos internos do sistema passou a ser o determinante. A crítica impressionista brasileira se adéqua ao processo epistemológico da primeira fase.
\end{abstract}

\author{
PALAVRAS-CHAVE \\ Impressionismo, crítica, semelhança, diferença \\ A crítica é uma representação do mundo tão pessoal, tão relativa, tão \\ interessante quanto aquelas que constituem os outros gêneros \\ literários. \\ Jules Lemaitre
}

\section{INTRODUÇÃO}

Este breve ensaio tem por objetivo refletir acerca do pensamento de Michel Foucault, prioritariamente sobre aquela linha desenvolvida em seu livro As palavras e as coisas, e sua relação com a crítica impressionista brasileira. Gostaríamos, antes de iniciar o desenvolvimento de nosso raciocínio, esclarecer que esta relação não é, de forma alguma, uma relação de causa e efeito, ou uma relação de influência de um suporte teórico, no caso o estruturalismo, sobre uma prática crítica, no caso o impressionismo, pois aquele é posterior ao “movimento” da crítica 
impressionista brasileira. O que pretendemos com esta aproximação é usar a teoria estruturalista, representada aqui (por mais que o autor negue esta filiação) por Foucault e sua obra seminal, As palavras e as coisas, para tentar entender algumas características da crítica impressionista. Dentre essas características, uma em especial vem sendo tema de nossos estudos há algum tempo, qual seja: a presença de elementos literários no texto crítico; em outras palavras, a literariedade do texto crítico, a fluidez verbal aliada ao rigor analítico que, ao mesmo tempo que aproxima o texto crítico do texto literário, não retira daquele seu poder de análise formal e conteudística sobre o texto criticado.

Para facilitar nosso esforço analítico e reduzir nosso campo de ação, já que a crítica impressionista brasileira abarca algumas décadas e dezenas de críticos renomados, nos centramos em duas emblemáticas figuras da chamada crítica impressionista: João Ribeiro e Álvaro Lins.

\section{A CRÍTICA DA PROSA DO MUNDO OU A CRÍTICA BASEADA NA SEMELHANÇA}

Um breve comentário de Foucault, que está inserido em uma emaranhada e complexa rede de raciocínio cujo autor tenta, mas nem sempre consegue, desembaraçar nas mais de 500 páginas de As palavra e as coisas, está na base de nosso estudo, além de ter desencadeado toda a linha de raciocínio que tentaremos traduzir, aqui, em palavras. A passagem citada é esta que reproduziremos a seguir: “O comentário se assemelha indefinidamente ao que ele comenta e que jamais pode enunciar."1

Foucault insere esse comentário no segundo capítulo de sua obra, intitulado de “A prosa do mundo”. Nesse capítulo, no anterior e nos próximos três, ou seja, na primeira parte de As palavras e as coisas, Foucault demonstra que o conhecimento, até o século 16, se construía com base na semelhança: "Vê-se que a experiência da linguagem pertence à mesma rede arqueológica a que pertence o conhecimento das coisas da natureza. Conhecer essas coisas era patentear o sistema das semelhanças que as tornavam próximas e solidárias umas às outras.”²

Ora, se o comentário se assemelha "indefinidamente" ao que ele comenta, isso quer dizer que o texto crítico, por definição, se assemelha ao texto criticado, sem contudo poder enunciá-lo.

\footnotetext{
${ }^{1}$ FOUCAULT. As palavras e as coisas, p. 57.

${ }^{2}$ FOUCAULT. As palavras e as coisas, p. 59.
} 
Foucault, dessa forma, encaminha nosso raciocínio na busca de uma semelhança entre o textobase e aquele outro texto que se escreve sobre ele, no caso o texto crítico. Levando em consideração que os textos-base, ou textos criticados que estamos tratando aqui, são textos literários - romances, poemas, crônicas, contos, etc.-, e nos apoiando na acertiva foucaultiana, concluímos que se o comentário se assemelha ao que ele comenta, o texto crítico, ao se assemelhar ao texto criticado, é literário como ele, ou seja, possui o que alguns teóricos chamam de "literariedade" e que Barthes nomeou de "escritura” (ecriture), em oposição à "escrevência" (ecrévain). Voltando a Foucault:

Da mesma forma, mas com alguma transposição, a linguagem se dá por tarefa restituir um discurso absolutamente primeiro que, no entanto, ela só pode enunciar se acercando dele, tentando dizer a seu propósito coisas semelhantes a ele, e fazendo nascer assim, ao infinito, as fidelidades vizinhas e similares de interpretação. ${ }^{3}$

É exatamente dessas fidelidades vizinhas e similares de interpretação que estamos tratando aqui. O texto crítico é, em última instância, uma interpretação analítica do texto-base, ou seja, do texto literário. As fidelidades vizinhas citadas por Foucault nos levam a concluir que o texto crítico tende, por uma questão de fidelidade à semelhança, se aproximar, em termos formais, ao texto criticado, assumindo assim características literárias. Observemos, a título de exemplificação, este trecho de um ensaio crítico escrito por Álvaro Lins (um dos grandes expoentes de nossa crítica impressionista) em 1942, sobre o humor na poesia de Carlos Drummond de Andrade:

E de onde vieram estes aspectos, e mais aquela emoção vencida e sufocada, aquela ternura que se cobre com um véu de ceticismo, aquele sentimento humano de fraternidade que está ferido pela contemplação do mundo, aquela ironia triste, aquele humor, aquele riso de quem disfarça soluços, aquele desencanto misturado de esperanças, aquela visão particular dos objetos, aquela nova dimensão para os espetáculos dos seres e das paisagens, aquela reserva feita disfarce para a sua contínua participação no destino dos homens, aquela inclinação para os humildes e os simples, aquela seriedade de homem voltado para as fontes da infância, aquela sensação do sentido trágico da vida? ${ }^{4}$

Percebemos aqui que essas “fidelidades vizinhas e similares de interpretação" citadas por Foucault, de forma alguma se confundem com uma imitação de estilo do autor criticado pelo

\footnotetext{
${ }^{3}$ FOUCAULT. As palavras e as coisas, p. 57. (grifo nosso)

${ }^{4}$ LINS. Os mortos de sobrecasaca, p. 13.
} 
autor crítico, mas sim uma penetração deste no universo formal daquele, ou seja, no campo da literatura (ou da escritura como preferia chamar Barthes). Álvaro Lins, no texto citado, exerce sua função de crítico literário, analisando e interpretando a obra do insigne poeta mineiro. Entretanto, em vários trechos, como nesse reproduzido acima, o autor se deixa levar, se permitindo voos mais arrojados no campo formal, sem, no entanto, perder de vista seu objeto de análise ou trocar de posição com ele. Percebemos que o autor repete inúmeras vezes os pronomes "aquele” e “aquela”, sempre acompanhados por características creditadas ao poeta: humor, ironia triste, visão particular, inclinação para os humildes, dentre outras, em um exercício puramente literário, em que as construções frasísticas possuem um ritmo e um tom que se aproximam mais de um texto poético ou ficcional do que de um texto crítico, como por exemplo: "aquela reserva feita disfarce para a sua contínua participação no destino dos homens” ou "aquela emoção vencida e sufocada” ou mesmo "aquela ternura que se cobre com um véu de ceticismo".

Contudo, voltamos a frisar, em momento algum, mesmo naqueles de maior enlevo poético, que o crítico perde a mirada analítica, preocupando-se sempre em dissecar a obra do poeta, tanto do ponto de vista formal e estrutural, quanto do ponto de vista do conteúdo Como no trecho que se segue, retirado do mesmo ensaio:

\begin{abstract}
Devemos levar assim, para a compreensão dessas poesias os nossos recursos de emoção e espírito crítico. Logo dominaremos aquele aparente estorvo de hermetismo, ilogicidade e complexidade. Tudo se resumindo na clarividência e no sensibilismo (sic) do leitor, que não deve confundir "sentido poético" com "sentido lógico", que deve aceitar a obra de um poeta como uma visão metafórica e não naturalista. Outra circunstância a levar em conta é a natureza humana do poeta diante da qual nos colocamos. Para os que vêem claro dentro do mundo, para os que se põem à luz do sol, a poesia será objetiva e límpida, para os que avançam nas trevas, para os que vêem se debatendo dentro da noite e dos mistérios sombrios a poesia há de ser subjetiva e densa. ${ }^{5}$
\end{abstract}

Podemos notar nesse trecho que Álvaro Lins inicia dizendo que o leitor, e também o crítico, que é antes de mais nada um leitor, deve usar os recursos da emoção e do espírito crítico para ler as "poesias" de Carlos Drummond de Andrade. Mais abaixo ele desenvolve seu raciocínio analítico acerca do poeta e sua poesia dizendo que o leitor deve usar sua sensibilidade para não confundir “sentido poético” com "sentido lógico”, e que a obra de um poeta, no caso, Drummond, deve ser aceita com uma visão “metafórica” e não “naturalista”. As já referidas

\footnotetext{
${ }^{5}$ LINS. Os mortos de sobrecasaca, p. 24.
} 
“fidelidades vizinhas e similares da interpretação”, citadas por Foucault, aparecem na última parte do trecho reproduzido, onde o crítico se imbui de um espírito literário semelhante, mas não idêntico e nem necessariamente da mesma qualidade, ao do poeta criticado, e escreve um trecho de rara beleza literária e de profundo tom poético, que vale a pena ser repetido aqui mais uma vez, a título de ilustração: "Para os que vêem claro dentro do mundo, para os que se põem à luz do sol, a poesia será objetiva e límpida; para os que avançam nas trevas, para os que vêem se debatendo dentro da noite e dos mistérios sombrios, a poesia há de ser subjetiva e densa.”

Para Michel Foucault, até o século 16 o conhecimento estava intimamente ligado à interpretação (conhecer é interpretar). Era inadequado, segundo o pensador francês, tratar da epistémê sem se referir ao ato da interpretação:

Saber consiste, pois, em referir a linguagem à linguagem. Em restituir a grande planície uniforme das palavras e das coisas. Em fazer tudo falar. Isto é, fazer nascer, por sobre todas as marcas, o discurso segundo do comentário. O que é próprio do saber não é nem ver nem demonstrar, mas interpretar. ${ }^{6}$

Para Foucault, tomando como base o trecho acima e toda linha de raciocínio desenvolvida por ele na primeira parte de As palavras e as coisas, o saber, até o século 16, consiste, basicamente, em linguagem se referindo à linguagem, ou seja, no discurso segundo do comentário. Comentário este que, como já demonstramos, assemelha-se ao que se comenta. O texto crítico se adéqua perfeitamente a esse raciocínio, a partir do momento que ali nós temos linguagem se referindo à linguagem, um discurso segundo que busca interpretar o discurso original e, no caso específico da crítica impressionista, se assemelhando a este discurso primeiro. Novamente citando Foucault: "O comentário se assemelha indefinidamente ao que ele comenta.”

Para o crítico impressionista o objeto criticado e o objeto crítico, na maioria das vezes, se confundem em sua forma, pois aqui temos literatura falando de literatura ou, como bem apontou Foucault, linguagem falando de linguagem. Nos textos ensaísticos dos críticos impressionistas (especificamente no caso que estamos tratando aqui, aqueles textos escritos por Álvaro Lins), percebemos, na maioria deles, uma subjetividade literária aliada a uma reflexão analítica, e ambas protegidas sob o manto de uma preocupada e bem definida, apesar de nem sempre muito

\footnotetext{
${ }^{6}$ FOUCAULT. As palavras e as coisas, p. 55. (grifo nosso)
} 
sistemática, metodologia crítica. Segundo Alexandre Barbosa: “(...) o esforço de fazer da matéria propriamente crítica uma matéria amoldável aos exercícios da imaginação do escritor.”7

Com a crítica impressionista surge a figura do crítico-autor, que, sem o intuito de ser uma superação da figura do crítico, parte de uma valorização da condição de autor do crítico. Acerca disso Alexandre Barbosa nos adverte:

Não se pense entretanto, que essa definição do crítico como leitor e escritor signifique o abandono eventual do rigor analítico, sem o qual aquela condição haveria de se desfazer em caprichosas impressões de leitura em que as possíveis interpretações não fossem mais do que simples palpites.”8

E completa:

(...) o que há de notável está precisamente em saber atingir o difícil equilíbrio entre a prosa que, para o leitor, corre fácil e dasataviadamente e a seriedade na exploração de métodos de análise adequados para as diversas obras e os mais variados autores sob escrutínio. ${ }^{9}$

Michel Foucault, logo no início do capítulo dois de As palavras e as coisas, nos diz que a semelhança desempenhou um papel de fundamental importância no saber da cultura ocidental até o fim do século 16, conduzindo a exegese e a interpretação dos textos. Até o momento, neste nosso pequeno estudo, temos partido da afirmação foucaultiana acerca da presença da semelhança na construção do saber, além de outras já citadas, como por exemplo: sua afirmação de o saber consistir em referir a linguagem à linguagem e de que o comentário se assemelha ao que ele comenta Contudo, um leitor mais atento de Foucault pode objetar, levando em consideração nosso raciocínio, que a crítica impressionista brasileira é uma ocorrência do século 20 (mais precisamente entre as décadas de 1930 e 1950, quando os textos desses autores, alcunhados impressionistas, ocupavam os principais jornais do país, chamados, um tanto pejorativamente, de crítica de rodapé), ao passo que a teoria da semelhança, em que o saber está no fato de a linguagem se referir à linguagem e o comentário se assemelhar ao que ele comenta (e assim se construir uma epistémê para um determinado período histórico, teoria esta defendida por Foucault em obra já citada), se aplica ao conhecimento até o século 16.

\footnotetext{
${ }^{7}$ BARBOSA. Augusto Meyer ensaísta, p. 15.

${ }^{8}$ BARBOSA. Augusto Meyer ensaísta, p. 15.

${ }^{9}$ BARBOSA. Augusto Meyer ensaísta, p. 15.
} 
Aceitamos a objeção mas não concordamos, pois é sabido que uma epistémê, mesmo estando ligada a um determinado momento histórico, pode ressurgir em outro momento ou em determinado grupo estético. Apesar da semelhança, segundo Foucault, estar na base da construção do conhecimento até o século 16, da diferença ser a pedra de toque da epistémê no período clássico e a relação dos elementos internos do sistema (modelo estruturalista) ser o novo espaço do saber a partir do século 19, nada impede que uma epistémê baseada na semelhança ressurja na contemporaneidade ligada a um determinado grupo, gênero literário e contexto histórico, pois não devemos esquecer que esta referida epistémê dominou toda a construção do pensamento humano, segundo Foucault, durante séculos, ou melhor, milhares de ano. É coerente acreditar em um atavismo da crítica impressionista, mesmo porque a crítica literária é indissociável de seu objeto de análise, ou seja, o objeto literário, e este, por sua vez, está em constante mutação, buscando muitas vezes elementos em estéticas dominantes do passado. O próprio Álvaro Lins nos diz:

Uma "tradição" esta sendo perquerida e incorporada de modo cada vez mais visível: gêneros, maneiras, formas e recursos da antiga arte poética vêem-se aproveitados pelos poetas modernos, mas não em termos de imitação decadentista ou cópia anacrônica. ${ }^{10}$

\section{A TEORIA CRÍTICA E O DISCURSO LITERÁRIO: JOÃO RIBEIRO, A SUPERAÇÃO DO ENSAIO PELA POESIA DO ENSAIO}

Essa presença de espaços literários no interior do texto crítico também é percebida naqueles ensaios que tratam de questões teóricas e estéticas ligadas a teoria literária e não apenas àqueles textos que tratam diretamente das produções literárias. Nesses ensaios teóricos não podemos falar de uma linguagem se referindo à linguagem ou do comentário se assemelhando àquilo que se comenta, pelo menos não diretamente, mas ainda estamos tratando da representação. Aqui não temos mais o texto literário que se imbrica com o texto crítico, em uma relação de puro hibridismo, em que o texto que crítica a criação se torna, ele mesmo, uma criação literária. O texto teórico se debruça sobre um conceito, uma teoria ou um elemento estético, no qual a linguagem, a linguagem do crítico, no caso a linguagem literária do crítico impressionista,

\footnotetext{
${ }^{10}$ LINS. Os mortos de sobrecasaca, p. 32.
} 
busca uma decifração. Lembrando a acertiva de Foucault: “As coisas se manifestam como linguagem e a linguagem como coisas a decifrar."11

O crítico João Ribeiro pode ser considerado um dos “precursores” de nossa crítica impressionista; além de seus ensaios críticos, em que analisa obras literárias (prosa e poesia), João Ribeiro possui uma série de ensaios teóricos nos quais discute questões de estética e filosofia literária. Páginas de estética, seu principal livro teórico, foi lançado em 1905. Nos pequenos ensaios que compõem esse livro podemos perceber a habilidade com que o autor entrelaça suas profundas reflexões analíticas com seu estilo sofisticado e elegante, criando trechos de literatura pura, como os reproduzidos a seguir, ao falar da forma literária, no ensaio intitulado “A forma literária”:

Essas argentárias e lantejoulas, na frase do clássico, entram no trajar de todos os tempos. A nudez dentro em breve gasta o assombro, enquanto o planejamento das vestes conserva como em cinzas a brasa candente da curiosidade. ${ }^{12}$

Porque é certo que, no polir e limar os seus trabalho, os autores suprimem ou aumentam, ou transpõe as palavras, como que lhes buscando os único trajes que lhes assentam. ${ }^{13}$

Ou ao falar de estilo, no ensaio "Estilo e forma literária”:

Nós outros brasileiros não temos por enquanto, por falta de personalidade étnica e política, um estilo nacional. Suspiramos, irresolutos e indecisos, por um tipo social, por um dialeto e uma forma civil. Não há pois, matéria para um grande estilista, propriamente. ${ }^{14}$

Ao dizer isso de forma tão literariamente arrojada, o crítico, por ilibada modéstia, não é capaz de vislumbrar em seu próprio texto um estilo próprio, sofisticado e nem por isso menos nacional.

Os ensaios críticos, assim como os ensaios teóricos dos autores impressionistas, não têm, em sua maioria, apenas a função de destacar sentidos na obra analisada ou refletir acerca de tópicos teóricos, mas também, no caso do ensaio crítico, de criar significações que enriqueçam a leitura do texto criticado e que deem autonomia literária ao texto segundo ou seja, ao texto

\footnotetext{
${ }^{11}$ FOUCAULT. As palavras e as coisas, p. 47.

${ }^{12}$ RIBEIRO. Páginas de estética, p. 26.

${ }^{13}$ RIBEIRO. Páginas de estética, p. 26.

${ }^{14}$ RIBEIRO. Páginas de estética, p. 20.
} 
crítico. Da mesma forma que o texto teórico de João Ribeiro, ao mesmo tempo que nos auxilia na compreensão dos elementos estéticos da literatura, se nos apresenta como uma peça literária autônoma, que poderia inclusive, como já aconteceu inúmeras vezes, tornar-se objeto estético da crítica. Augusto Meyer, certa vez, analisando a obra de João Ribeiro, disse que nesta o ensaio da poesia era substituído pela poesia do ensaio. Sendo assim, prefiro acreditar mais na obra do que no autor, e discordar de João Ribeiro, quando diz que: “Ao crítico é que se atribuem destruições ou o desígnio de ruínas; de qualquer maneira é espírito negador e destrutivo, como acontece ao que elege e escolhe ou sequer explica.” ${ }^{15}$ Não. João Ribeiro, assim como Álvaro Lins, Augusto Meyer, Sérgio Milliet, Otto Maria Carpeaux e vários outros expoentes da crítica impressionista, eram criadores também, se não no conteúdo, quase sempre analítico, pelo menos na forma, muitas vezes tão elaborada e literária quanto do objeto criticado.

\section{A CRÍTICA COMO GÊNERO LITERÁRIO DE CRIAÇÃO}

A maioria dos críticos impressionistas (João Ribeiro é uma exceção discordante) viam a crítica como um gênero literário de criação, em que o texto primeiro, sem perder jamais sua importância e primazia, muitas vezes projetava o texto segundo, aquele que surgia a partir dele, ou seja, o texto crítico, dando a este último uma autonomia, na qual a "semelhança" na forma literária vem acompanhada da diferença no estilo e no conteúdo. Em um ensaio sobre Karl Kraus, Walter Benjamin nos diz o seguinte sobre a questão do estilo:

Se estilo é o poder de nos movimentarmos em toda extensão do pensamento lingüístico sem cair na banalidade, é obtido principalmente pelo vigor dos grandes pensamentos, que transporta o sangue da linguagem através dos capilares da sintaxe até os membros mais remotos. ${ }^{16}$

Era exatamente isso que o crítico impressionista buscava realizar, muitas vezes inconscientemente, em sua obra. Seu estilo, sua forma literária, era sua capacidade de se movimentar por toda a extensão da linguagem, auxiliado por sua erudição e sua condição de leitor diferenciado, e dessa maneira criar um texto segundo, um texto crítico que mesmo partindo de um texto primeiro, objeto da crítica, se distinguia deste, tanto na forma quanto no conteúdo.

\footnotetext{
${ }^{15}$ RIBEIRO. Páginas de estética, p. 34.

${ }^{16}$ Benjamin, citado por SONTAG. Sob o signo de saturno, p. 101.
} 
Aqui temos a busca pela semelhança criando um texto diferente e com identidade própria, mesmo tendo como princípio norteador essa própria busca pela semelhança.

Essa relação ambígua entre o texto crítico impressionista e o texto criticado (em que ao mesmo tempo que há uma busca pela semelhança por parte do texto segundo, através de uma escrita literária que se aproxima do texto primeiro, há também uma busca pela diferença e por uma identidade própria, que torna esse texto segundo uma obra autônoma e possível objeto de crítica em um segundo momento) pode ser melhor entendida se analisarmos com cuidado o Capítulo 3 de As palavras e as coisas, no qual Foucault demonstra que a partir do século 17 instaura-se a era clássica, em que a diferença assume o lugar da semelhança na construção do saber, na epistémê, mantendo a semelhança, contudo, um papel de “(...) fundo indiferenciado, movediço, instável, sobre o qual o conhecimento pode estabelecer suas relações, suas medidas e suas identidades." ${ }^{17}$ Analisemos com a atenção o trecho que se segue, pois ele é bastante elucidativo acerca do que acabamos de dizer:

No século XVI, a semelhança estava ligada a um sistema de signos; e era sua interpretação que abria o campo dos conhecimentos concretos. A partir do século XVII, a semelhança é repelida para os confins do saber, do lado de suas mais baixas e humildes fronteiras. Lá, ela se liga à imaginação, às repetições incertas, às analogias nebulosas. $\mathrm{E}$ em vez de desembocar numa ciência da interpretação, implica uma gênese que ascende dessas formas rudes do Mesmo aos grandes quadros do saber desenvolvidos segundo as formas da identidade, da diferença e da ordem. ${ }^{18}$

Essa relação contraditória, diríamos até mesmo dialética, entre a semelhança e a diferença, que Foucault nos apresenta, nos ajuda a entender a relação do texto crítico impressionista com o texto base ou texto criticado. Quando Foucault fala que a partir do século 17 "a semelhança é repelida para os confins do saber, onde se liga à imaginação, às repetições incertas e às analogias nebulosas”, isso nos remete à busca empreendida pelo texto crítico de uma identidade própria, identidade esta que, contudo, ainda se encontra de alguma forma ligada ou referencializada ao texto-base. O próprio Foucault complementa que a partir do século 17 a semelhança "em vez de desembocar numa ciência da interpretação, implica numa gênese que ascende dessas formas rudes aos grandes quadros do saber desenvolvidos segundo as formas da identidade e da diferença.” É exatamente o que percebemos na crítica impressionista; não há aqui uma

\footnotetext{
${ }^{17}$ FOUCAULT. As palavras e as coisas, p. 94.

${ }^{18}$ FOUCAULT. As palavras e as coisas, p. 98.
} 
objetivação pura e simples da interpretação em si mesma. A função do crítico é produzir sentidos, partindo das obras de outros autores e fazer desse sentido sua própria obra. O crítico impressionista evita desembocar em uma ciência da interpretação, seu caminho, nem sempre consciente, é em ascensão a um texto autônomo, de identidade própria, diferente na forma e no conteúdo mas semelhante na linguagem (literária e poética).

A professora Eneida Maria de Souza resume o que expomos acima de uma forma muito clara e objetiva em um trecho de seu texto "Crítica em palimpsesto.”

Pelo fato de a ficção ser objeto de análise da crítica literária e manter com ela uma convivência contínua, possibilita o entrelaçar de elos discursivos, dotando o texto teórico de marcas ficcionais, não precisando haver, necessariamente, simbiose entre as duas modalidades. Deve-se ainda ressaltar que o manuseio da linguagem, comum a ambos os dircursos, incita o jogo com o signos e a inexistência de barreiras rígidas entre textos que, embora diferentes, mantém alguma homologia de traços.

Em As palavras e as coisas, Michel Foucault pretende, e isso ele deixa bem claro em seu prefácio, realizar um estudo arqueológico, no qual é trazido à luz a epistémê e sua história no pensamento ocidental: "Neste relato o que deve aparecer são, no espaço do saber, as configurações que deram lugar às formas diversas do conhecimento empírico.”19 Nesse estudo ele divide a epistémê em três fases; aquela que vai até o final do século 16, em que o conhecimento é baseado na semelhança; a era clássica, que vai do século 17 até o início do século 19, em que o saber é construído sob a égide da diferença e da identidade; e finalmente, a era da modernidade, no qual o saber se constrói em um espaço de relações internas, um espaço de organizações, ou seja, um "sistema”. Como a crítica literária, e no caso específico deste estudo, a crítica impressionista faz parte desse "sistema", procuramos aplicar alguns conceitos desenvolvidos por Foucault. E concluímos que o movimento dialético, que Foucault prefere chamar de "ambíguo", existente entre a semelhança e a diferença, até a época moderna, e porque não dizer (apesar de Foucault não deixar isso bem claro, pois escreve de dentro da modernidade) modernidade à dentro, determinou a relação e a forma do texto crítico impressionista, tornando-o um texto detentor de um identidade própria, mas sem jamais perder de vista o texto-base com o qual se assemelha no plano do literário.

\footnotetext{
${ }^{19}$ FOUCAULT. As palavras e as coisas, p. XIX.
} 


\begin{abstract}
For Foucault, the epistémê process of the western civilization passes for three moments: up to the sixteenth century, it was tied to the similarity concept; from the sixteenth century, to the difference concept. In the twentieth century, the relation of the internal elements of the system started to be the determinative one. The Brazilian impressionist criticism is adapted to the process epistemológico of the first phase.
\end{abstract}

KEYWORDS

Impressionism, critique, semblance, difference

\title{
REFERÊNCIAS
}

BARBOSA, João Alexandre. Augusto Meyer ensaísta. Cult, São Paulo, n. 54, p. 14-17, jan. 2002.

BARTHES, Roland, Escritores e Escreventes. In: Crítica e verdade. 2. ed. Trad. Leyla Perrone Moisés. São Paulo: Perspectiva, 1999. p. 31-39.

FOUCAULT, Michel. As palavras e as coisas. 2. ed. Trad. Salma Tannus Muchail. São Paulo: Martins Fontes, 2002.

FOUCAULT, Michel. A arqueologia do saber. Trad. Luiz Felipe Baeta Neves. Rio de Janeiro: Forense Universitária, 2005.

LINS, Álvaro. Os mortos de sobrecasaca. Rio de Janeiro: Civilização Brasileira, 1963.

RIBEIRO, João. Páginas de estética. Lisboa: Livraria Clássica Editora de A. M. Teixeira, 1905.

SONTAG, Susan. Sob o signo de saturno. Trad. Ana Maria Capovilla e Albino Poli Jr. São Paulo: L\&PM, 1986

SOUZA, Eneida Maria de. Luiz Costa Lima: crítica em palimpsesto. Belo Horizonte: FALE/UFMG, 1993 (Cadernos do NAPq, número 7). 